\title{
Development of an Ergonomic Checklist for the Investigation of Work-related Upper Limb Disorders in Farming - AULA: Agricultural Upper-Limb Assessment
}

\author{
Yong-Ku Kong ${ }^{1}$, Soo-Jin Lee ${ }^{2}$, Kyung-Suk Lee ${ }^{3}$, Jun-Goo Han ${ }^{1}$, Dae-Min Kim ${ }^{1}$ \\ ${ }^{1}$ Department of Industrial Engineering, Sungkyunkwan University, Suwon, 440-746 \\ ${ }^{2}$ Department of Occupational and Environmental Science, College of Medicine Hanyang University, Seoul, 133-792 \\ ${ }^{3}$ Rural Resources Development Institute, NIAST, RDA, Suwon, 441-857
}

\begin{abstract}
Objective: The aim of this study was to develop an ergonomic checklist (AULA: Agricultural Upper-Limb Assessment) which can assess the risks of the work-related upper limb disorders of farming tasks in Korea. Background: There are few assessment tools that reflect the current condition of agricultural works as of now. Method: AULA was developed as following three stages. First of all, a physiological experiment was conducted with selected 14 upper limb postures which are frequently occurred in farming tasks and then, an ergonomic checklist was developed with determining risk levels of each body posture based on the experimental findings. Lastly, the ergonomic checklist was validated by comparing with the existing assessment tools. Results: When comparing the AULA which was developed in this study with the existing assessment tools, it was found that the AULA may get over limits of the existing ones which are sensitive to particular postures, but aren't sensitive to the rest of them. Conclusion: It is predicted that the developed upper limb posture assessment tool which gets over the existing tools' limits and is proper for domestic farm work conditions, will help to reduce musculoskeletal disorders caused by farm works, by assessing farm works more easily and objectively. Application: By further developing the theoretical groundwork on the induction of muscular skeletal system symptoms relating to agricultural works, it is expected to improve the level of preventing and managing such muscular skeletal system symptoms in the field of agricultural and farming works, which is relatively less advanced in terms of labor difficulties.
\end{abstract}

Keywords: Upper body postures, Ergonomics checklist, Farming tasks

\section{Introduction}

근골격계질환이란 근육, 건 그리고 신경 등에 일어나는 통증을 동반한 질환들을 총칭하는 말로서, 주로 작업 활동이 반복적이며 지속적이고, 부자연스러운 작업 자세로 인하여 발생할 확률이 높다고 한다(한국산업안전보건공단, 2000). 이러한 근골격계질환은 통증을 동반하여 작업자에게 심리적,
정신적 고통으로 인한 생산성 감소 등의 경제적 손실을 가중 시킨다(Chaffin et al., 1999). 이에 근골격계질환의 발병을 낮추고자 작업위험요인과 관련하여 선행연구들이 진행되었 다(Keyserling et al., 1993; Punnett et al., 1998; Tomas et al., 1999). 그러나 통계청에서 정리한 산업재해 현황에 따르면 우리나라의 경우, 근골격계질환자의 수가 2003년부 터 꾸준히 증가하고 있는 추세이며, 특히 2007년부터는 작 업관련성 질병 발생비율이 전체 재해자 수의 $80 \%$ 를 넘게

Corresponding Author: Dae-Min Kim. Department of Industrial Engineering, Sungkyunkwan University, Suwon, $440-746$.

Mobile: 010-8670-6148, E-mail: kimdaemin@skku.edu

Copyright@2011 by Ergonomics Society of Korea(pISSN:1229-1684 eISSN:2093-8462). All right reserved. 
차지하게 되었다. 그리하여 최근 국내에서도 근골격계질환 의 심각성을 깨닫고 2003 년에 근골격계질환의 예방관리를 위해 산업안전보건법에 근골격계질환 예방 의무 조항이 신 설되었고, 근골격계 부담 작업 유해요인조사 지침(KOSHA Code $\mathrm{H}-30)$ 과 사업장 근골격계질환 예방관리 프로그램 지 침(KOSHA Code $\mathrm{H}-31)$ 이 공표되었다.

농촌인구의 고령화와 여성 농업인구의 증가로 인해 농업 인의 근골격계질환 유병률 또한 증가 추세를 보이고 있으며, 특히 근골격계질환 유병률로는 주로 허리, 어깨 및 다리/무 릎 등의 부위에 집중되어 있다. 농작업자들의 근골격계질환 의 원인으로는 농작업 특성상 부적절한 작업 자세와 더불어 반복적인 동작이나 무리한 힘의 사용, 진동 및 온도 등을 들 수 있다.

현재 개발된 상지관련 평가지표(RULA, REBA, OWAS, Strain Index 등)들은 산업체 중심의 평가지표로써 우리나 라 농작업의 특성에 맞게 개발되지 않았으며, 나라별 작업자 들의 신체구조나 근력 및 크기 등의 다양성으로 인해, 우리 나라 농작업자들을 대상으로 적용하기에 적합하지 않기 때 문에, 우리나라의 농작업의 특성을 고려한 농작업자들의 상 지 관련 근골격계질환의 유병률에 대한 예측 및 평가체계를 갖춘 특성화된 인간공학적 평가지표 개발이 필요하다. 현재 Kong et al. (2011)에서 개발한 하지의 인간공학적 평가지표 와 더불어, 상지와 하지를 균형 있게 고려한 통합된 체계를 갖춘 농작업 중심의 한국형 평가체계가 필요하다.

현재 여러 작업들의 근골격계 위험요인을 평가하기 위한 도구로서 RULA, REBA, OWAS, Strain Index 등의 평가 체계를 범용으로 사용하고 있는데, 대부분은 제조업체 근로 자들을 대상으로 개발되었으므로, 우리나라 농작업 활동을 평가하기에 매우 제한적이며 한계가 있다. 특히, 무릎의 굽 힘과 더불어 허리의 숙임 동작이나, 목의 젖힘 동작과 함께 어깨 위로 팔을 들고 반복적인 수작업 등과 같은 전형적인 한국형 농작업에 대한 근골격계질환 유해요인을 특성화하여 평가할 수 있는 평가체계의 개발이 전무한 상태이다. 기존의 많은 연구들이 $90^{\circ}$ 까지의 어깨 높임 위치에서의 작업장에서 작업자의 선호도나 근육의 피로도를 중심으로 연구가 진행 되었다(Oberg et al., 1994; Carpenter et al., 1998). 농작 업에 특성화된 상지 중심의 평가체계 개발의 필요성이 있는 개발도상국의 경우에는 인간공학 학문적 체계가 부족하며, 인간공학 연구가 활발한 선진국의 경우에는 농작업에 특성 화된 상지 중심의 평가체계 개발 필요성에 대한 인식이 부 족하다.

국내의 경우, 농작업 중심의 평가체계의 부재로, 기존의 산업체 중심으로 개발된 인간공학적 평가체계를 농작업 평 가에 적용하고 있다. 농작업 재해 중 농업인의 근골격계 증 상 유병률과 신체발생 부위에 대한 연구, 그리고 그에 대한
원인 등의 연구를 통해 농작업 중심의 평가체계의 시급함을 인식하였고, 농작업에 특성화된 하지 중심의 인간공학적 평 가체계에 대한 연구는 진행되고 있으나, 상지 및 요추부 작 업에 대한 연구는 수행되지 못하고 있는 현실이다.

산업현장에서는 쉽게 볼 수 없지만, 농작업에서 흔히 관측 되는 목의 젖힘 자세나, 어깨나 머리 위로의 상지 올림 자세 등과 같은 작업 자세에 대한 연구가 미비한 상태이며, 국외 에서는 농작업에서 무거운 물건을 들거나 미는 등의 힘든 작업에 대해서 성인이 아닌 청소년들의 상지나 하지의 신체 부담 정도에 대한 연구가 진행되고 있지만, 농작업의 자세에 대한 연구는 미비한 상태이다.

따라서, 본 연구는 우리나라 농작업 및 농작업자 특성을 반영하는 상지와 허리 관련 근골격계질환 위험도를 평가할 수 있는 인간공학적 평가도구를 개발하고 적용하고자 한다.

\section{Methods}

본 연구에서는 농작업에서 발생하는 다양한 작업 자세에 관련하여 보다 정확한 인간공학적 상지 평가도구를 개발하 기 위해 본 연구팀의 선행 연구 Kong et al.(2010)에서 인 간공학적 하지 평가도구 개발에 사용된 개발체계와 같은 과 정을 사용하였다.

\subsection{Human physiological experimental method}

인체생리학적 실험 방법은 선행 연구(Kong et al., 2011) 의 실험 방법 및 실험 결과를 사용하였다. 본 실험에서는 실험을 지원한 남녀 대학생 및 대학원생 총 20명을 대상으 로 실험을 실시하였다. 피실험자들의 평균 연령은 25.4세 ( \pm 2.46$)$ 이며, 신장 및 몸무게의 평균은 각각 $175.93 \mathrm{~cm}$ (士4.37), 71.93kg $( \pm 6.41)$ 이었다. 상지의 주요 자세인 14 개의 실험 자세(Table 1)에 주관적 불편도, 심박수, 그리고 각 근육의 근전도를 측정하였다. 주관적 불편도는 Borg's RPE, $\mathrm{CR}-10$ scale을 사용하였으며, 근전도 측정 에 사용된 근육으로는 척추세움근(Erector Spinae), 삼각근 (Anterior Deltoid), 승모근(Upper Trapezius), 그리고 삼 두근(Triceps Brachii)을 평가하였다.

\subsection{Development of ergonomic evaluation tool}

상지 자세에 대한 평가도구 개발 과정은 Kong et al. (2010)의 하지 체크리스트 개발 단계와 동일하게 개발하였 다. 인체생리학적 실험 결과를 토대로 3 단계 - 첫째, 작업 
자세에 대한 위험수준 설정, 둘째, 노출시간에 대한 위험수 준 설정, 셋째, 작업 자세와 작업시간을 함께 고려한 위험수 준 설정 - 과정을 거쳐 농작업 관련 상지 자세의 인간공학 적 평가도구를 개발하였다.

\subsubsection{Decision risk level for work posture}

생리학적 실험 단계를 통해 얻은 평균 불편도, 평균 심박 수 그리고 평균 근전도 값들의 통계적 분석 결과 유의한 결 과를 보이는 그룹에 따라 위험도 점수를 분배하여 작업 자 세에 대한 위험수준을 결정하였다.

Table 1. 14 experimental upper body postures (B: Back, S: Shoulder, E: Elbow)

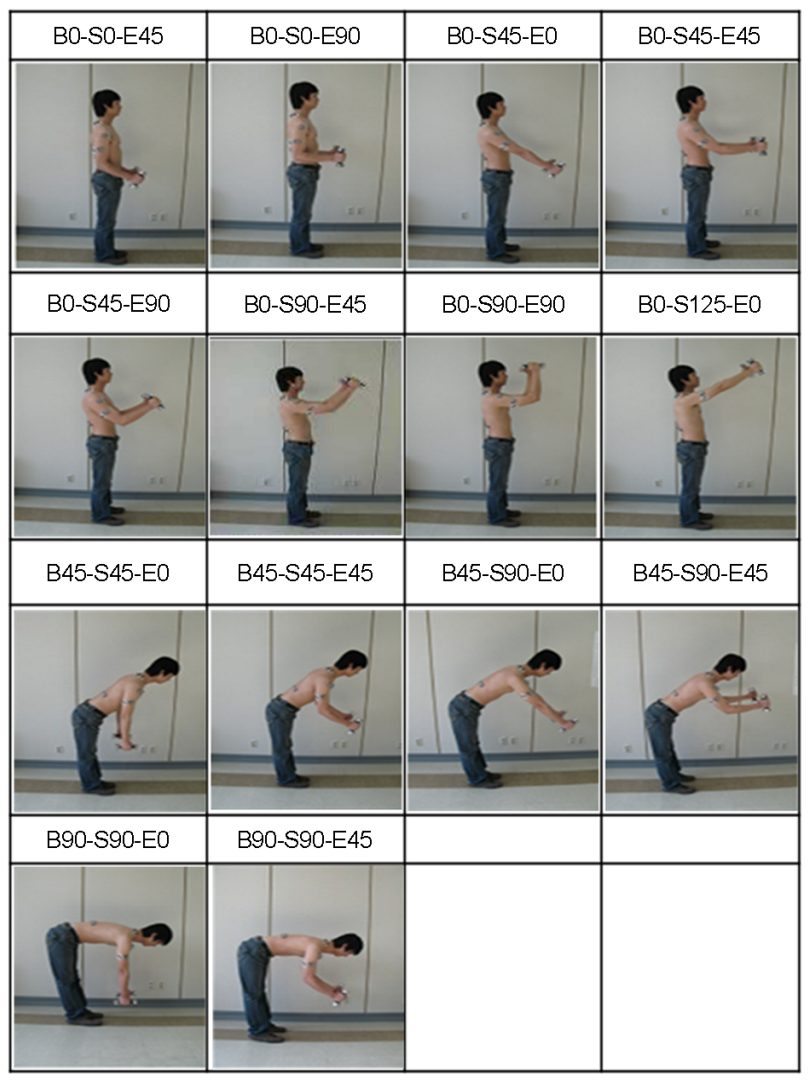

각 변수들의 값에 따라 4 개의 그룹으로 나누어 작은 그룹 부터 큰 그룹까지 1점에서 4점의 점수를 부여하였다. 따라 서, 불편도가 가장 낮은 그룹에 1 점, 불편도가 가장 높은 그 룹에 4점을, 심박수는 심박수가 가장 낮은 그룹에 1점, 심박 수가 가장 높은 그룹에 4점을 할당하였다. 반면, 근전도는 주파수를 통해 피로도 분석하여 각 근육의 피로 여부에 따라 피로함이 없으면 0점과 피로함이 있으면 1점으로 분배하였 다. 피로 여부는 각 자세에 대한 근전도를 측정할 때 초기와
말기 근전도의 주파수를 비교하여 말기 주파수가 초기 주파 수보다 낮게 나타나면 근육이 피로하였다고 가정하여 1점을 부여하고, 그렇지 않은 경우에는 근육이 피로하지 않았다고 가정하여 0점을 부여하였다(Hyun and Kim, 1997; Minning et al., 2007). 각 자세 별로 각 변수에 부여된 점수를 합하 여 최종 위험도를 산출하였다.

\subsubsection{Decision risk level for exposure time}

14 자세에 대하여 3 분마다 측정된 불편도 결과를 기초로 회귀식을 구하여 노출시간에 대한 위험수준을 결정하였다. 회귀식을 통해 산출된 불편도 값들을 Borg's RPE와 Borg's 10 points 모델을 참고하여 위험수준을 4단계로 재 분류하 였다.

\subsubsection{Decision of risk level that consider posture and time}

작업 자세에 대한 위험수준을 결정하고, 노출시간에 대한 위험수준 결과를 통합하여, 작업 자세뿐만 아니라 작업 자 세와 노출시간을 모두 고려한 체크리스트를 개발하였다.

\subsection{Comparative analysis of ergonomic assessment tool developed}

기존 인간공학적 평가도구와 본 연구에서 개발된 인간공 학적 평가도구를 비교 분석하여 우리나라 농작업 분석에의 적용 가능성을 검토하고자 하였다. 특히, 상지 관련 실제 농작업 자세들의 근골격계질환 위험도 분석을 위해 현재 널 리 사용되고 있는 인간공학적 평가도구인 RULA, REBA, OWAS 등과 본 연구를 통해 개발된 체크리스트와 비교 분 석하였다.

\section{Results}

\subsection{Development of upper limb ergonomic assessment tool}

\subsubsection{Decision of risk level about posture}

Method for score distribution

Table 2와 같이 평균 불편도와 평균 심박수를 이용한 점 수 분배 결과를 살펴보면, 불편도에 따른 몸 전체의 점수를 분배한 결과 B0-S120-E0, B45-S90-E0일 때 가장 높 은 점수 4 점을, 서있는 자세에서 팔을 $45^{\circ}, 90^{\circ}$ 로 들었을 때 1 점을 할당 받았다. 각 국소 부위 중 허리의 점수는 허리 각도가 $45^{\circ}$ 일 때 가장 높은 점수를 받았으며, 서있는 자세에 
Table 2. Score for each body posture based on the analyses of discomfort and heart rate (B: Back, S: Shoulder, E: Elbow)

\begin{tabular}{|c|c|c|c|c|c|}
\hline & & 4 & 3 & 2 & 1 \\
\hline \multirow{4}{*}{$\begin{array}{l}\text { Subjective } \\
\text { rating }\end{array}$} & $\begin{array}{l}\text { Whole } \\
\text { body }\end{array}$ & B0-S120-E0, B45-S90-E0 & $\begin{array}{c}\text { B0-S90-E45, B0-S90-E90, } \\
\text { B45-S45-E0, B45-S45-E45, } \\
\text { B45-S90-E45, B90-S90-E0, } \\
\text { B90-S90-E45 }\end{array}$ & $\begin{array}{c}\text { B0-S45-E0, B0-S45-E45, } \\
\text { B0-S45-E90 }\end{array}$ & B0-S0-E45, B0-S0-E90 \\
\hline & Back & $\begin{array}{l}\text { B45-S45-E0, B45-S45-E45, } \\
\text { B45-S90-E0, B45-S90-E45 }\end{array}$ & B90-S90-E0, B90-S90-E45 & B0-S90-E45, B0-S120-E0 & $\begin{array}{l}\text { B0-S0-E45, B0-S0-E90, } \\
\text { B0-S45-E0, B0-S45-E45, } \\
\text { B0-S45-E90, B0-S90-E90 }\end{array}$ \\
\hline & Shoulder & B0-S120-E0 & B0-S90-E45, B0-S90-E90 & $\begin{array}{l}\text { B0-S45-E0, B0-S45-E45, } \\
\text { B0-S45-E90, B45-S45-E45, } \\
\text { B45-S90-E0, B45-S90-E45 }\end{array}$ & $\begin{array}{c}\text { B0-S0-E45, B0-S0-E90, } \\
\text { B45-S45-E0, B90-S90-E0, } \\
\text { B90-S90-E45 }\end{array}$ \\
\hline & Arm & B0-S120-E0 & B0-S90-E45, B0-S90-E90 & $\begin{array}{c}\text { B0-S45-E0, B0-S45-E45, } \\
\text { B0-S45-E90, B45-S90-E0, } \\
\text { B45-S90-E45 }\end{array}$ & $\begin{array}{l}\text { B0-S0-E45, B0-S0-E90, } \\
\text { B45-S45-E0, B45-S45-E45, } \\
\text { B90-S90-E0, B90-S90-E45 }\end{array}$ \\
\hline \multicolumn{2}{|c|}{$\begin{array}{l}\text { Heart } \\
\text { rating }\end{array}$} & $\begin{array}{c}\text { B0-S90-E45, B0-S90-E90, } \\
\text { B0-S120-E0, B45-S45-E45, } \\
\text { B45-S90-E0, B45-S90-E45, } \\
\text { B90-S90-E45 }\end{array}$ & $\begin{array}{l}\text { B0-S45-E0, B0-S45-E45, } \\
\text { B0-S45-E90, B90-S90-E0 }\end{array}$ & B0-S0-E45, B45-S45-E0 & B0-S0-E90 \\
\hline
\end{tabular}

Table 3. Score for each body posture based on the frequency analyses of muscle activities(ES: Erector Spinae, AD: Anterior Deltoid, UT: Upper Trapezius, TB: Triceps Brachii, B: back, S: shoulder, E: Elbow)

\begin{tabular}{c|c|c|c|c|c|c|c}
\hline & \multicolumn{2}{|c|}{ Back } & \multicolumn{3}{c|}{ Shoulder } & \multicolumn{2}{c}{ Arm } \\
\cline { 2 - 9 } & ES & Score & AD & UT & Score & TB & Score \\
\hline B0-S0-E45 & 1 & 1 & 1 & 1 & 2 & 1 & 1 \\
\hline B0-S0-E90 & 1 & 1 & 1 & 1 & 2 & 1 & 1 \\
\hline B0-S45-E0 & 1 & 1 & 1 & 1 & 2 & 1 & 1 \\
\hline B0-S45-E45 & 1 & 1 & 1 & 1 & 2 & 1 & 1 \\
\hline B0-S45-E90 & 1 & 1 & 1 & 1 & 2 & 1 & 1 \\
\hline B0-S90-E45 & 1 & 1 & 1 & 1 & 2 & 1 & 1 \\
\hline B0-S90-E90 & 1 & 1 & 1 & 1 & 2 & 1 & 1 \\
\hline B0-S120-E0 & 1 & 1 & 1 & 1 & 2 & 1 & 1 \\
\hline B45-S45-E0 & 1 & 1 & 1 & 1 & 2 & 1 & 1 \\
\hline B45-S45-E45 & 1 & 1 & 1 & 1 & 2 & 1 & 1 \\
\hline B45-S90-E0 & 1 & 1 & 1 & 1 & 2 & 1 & 1 \\
\hline B45-S90-E45 & 1 & 1 & 1 & 1 & 2 & 1 & 1 \\
\hline B90-S90-E0 & 0 & 0 & 0 & 1 & 1 & 1 & 1 \\
\hline B90-S90-E45 & 0 & 0 & 1 & 0 & 1 & 1 & 1 \\
\hline
\end{tabular}

서 즉 허리 각도가 $0^{\circ}$ 일 때 가장 낮은 점수를 할당 받았다. 어깨와 팔은 대체로 어깨의 각도가 $90^{\circ}$ 또는 $120^{\circ}$ 일 때, 높은 점수를 받았다. 심박수에 따른 점수의 경우에는 $\mathrm{B} 0-$ S0-E90 자세에서 가장 낮은 점수를 할당 받았다. Table 3 은 근전도의 피로도 분석을 통해 근육의 피로 여부를 각
근육 별, 각 부위 별 점수를 보여주고 있다. 허리의 경우 B90-S90-E0, B90-S90-E45를 제외한 모든 자세에서 시간이 지남에 따라 근육의 피로가 발생하여 1점을 받았으 며, 허벅지 또한 허리와 마찬가지로 두 자세를 제외한 모든 자세에서 삼각근과 승모근 두 근육 모두 피로가 발생하여 두 근육의 점수를 합한 2점을 받았으며, B90-S90-E0은 승모 근의 피로로 인해 1점, B90-S90-E45는 삼각근의 피로로 인해 1점을 받았다. 팔 근육인 삼두근은 모든 자세에서 근육 의 피로가 발생하였다.

\section{Drawing up an assessment table}

3.1.1절의 (1)점수 분배 방법을 기반으로 평가 항목표를 작성하기 위해서는 종속변수 별(불편도, 심박수, 근전도) 해 당하는 부위의 점수를 기입한 후 각 부위에 따른 평균값의 평균을 구하게 된다. 예를 들어 B45-S45-E45의 경우 불 편도 점수는 Table 2 에 의하면 전신의 각 종속변수 별 점수 가 불편도, 심박수가 각각 3,4 점이며, 평균은 3.5 점에 해당 되고, 허리의 경우 불편도, 근전도 점수가 각각 4,1 점씩으로 평균은 2.5 점이며, 어깨의 경우는 불편도, 근전도 점수가 각 2점씩으로 평균은 2점이며, 팔의 경우는 불편도, 근전도 점 수가 각각 1 점씩으로 평균은 1 점이다. 전신과 각 국소 부위 의 평균의 평균은 2.25 점이 된다(Table 4).

위와 같은 방법으로 14 가지 자세에 대하여 점수를 구하였 고, 최종적으로 점수가 높은 것부터 순서대로 나열하고 분포 상의 특성을 고려하여, 위험수준과 평가를 다음의 Table 5 과 같이 4 단계로 구분하였다.

위험수준이 가장 낮은 1 수준은 자세 별 위험 점수가 1.13 
Table 4. An example about each posture scoring(B45-S45-E45)

\begin{tabular}{|c|c|c|c|c|c|}
\hline & Whole body & Back & Shoulder & Arm & \\
\hline $\begin{array}{l}\text { Subjective } \\
\text { rating }\end{array}$ & 3 & 4 & 2 & 1 & \\
\hline $\begin{array}{l}\text { Heart } \\
\text { rating }\end{array}$ & \multicolumn{2}{|l|}{4} & \multicolumn{2}{|l|}{-} & \\
\hline EMG & - & 1 & 2 & 1 & AVG. \\
\hline AVG. & 3.5 & 2.5 & 2 & 1 & 2.25 \\
\hline
\end{tabular}

Table 5. An assessment of risk level scores of each posture and their risk levels

\begin{tabular}{|c|c|c|}
\hline Posture & Score & Risk level \\
\hline B0-S0-E90 & 1.13 & \multirow{2}{*}{1 / Medium } \\
\hline B0-S0-E45 & 1.25 & \\
\hline B90-S90-E0 & 1.63 & \multirow{6}{*}{2 / Little high } \\
\hline B90-S90-E45 & 1.75 & \\
\hline B0-S45-E0 & 1.75 & \\
\hline B0-S45-E45 & 1.75 & \\
\hline B0-S45-E90 & 1.75 & \\
\hline B45-S45-E0 & 1.88 & \\
\hline B0-S90-E90 & 2.25 & \multirow{5}{*}{3 / High } \\
\hline B45-S45-E45 & 2.25 & \\
\hline B0-S90-E45 & 2.38 & \\
\hline B45-S90-E45 & 2.38 & \\
\hline B45-S90-E0 & 2.50 & \\
\hline B0-S120-E0 & 2.75 & 4 / Very high \\
\hline
\end{tabular}

1.25이었고, B0-S0-E90, B0-S0-E45 자세가 해당 되었으며, 2수준 자세 별 위험 점수는 1.63 1.88이었으며 B90-S90-E0, B90-S90-E45, B0-S45-E0, B0$\mathrm{S} 45-\mathrm{E} 45, \mathrm{~B} 0-\mathrm{S} 45-\mathrm{E} 90, \mathrm{~B} 45-\mathrm{S} 45-\mathrm{E} 0$ 자세가 해당되 었다. 또한 위험수준 3에 해당하는 자세인 $\mathrm{BO}-\mathrm{S} 90-\mathrm{E} 90$, B45-S45-E45, B0-S90-E45, B45-S90-E45, B45$\mathrm{S} 90-\mathrm{E} 0$ 의 위험 점수는 2.25 2.50였으며, 위험수준이 가 장 높은 4수준은 자세 별 위험 점수가 2.75 였으며 해당되 는 자세는 B0-S120-E0이었다.

\subsubsection{Decision of risk level about exposure time}

\section{Method for score distribution}

14 자세에 대하여 3 분마다 측정된 불편도 결과를 기초로 회귀식을 구하였다(Table 6). 회귀식에서 $\mathrm{x}$ 에 노출시간(분) 을 대입하면 신체 불편도 값 $\mathrm{y}$ 가 산출되게 된다(Table 7). 이때 신체 불편도 값의 경우 신체 부위 전체는 Borg's RPE
점수를 의미하며, 국소 부위(허리, 어깨, 팔)의 경우에는 Borg's 10 points를 의미한다.

Table 6. A regression equation about duration and discomfort changes of each work posture [whole body(W), back(B), shoulder(S), arm(A)]

\begin{tabular}{c|c|c}
\hline \multirow{4}{*}{ B0-S0-E45 } & W & $\mathrm{y}=0.57 \mathrm{x}+7.63$ \\
\cline { 2 - 3 } & $\mathrm{B}$ & $\mathrm{y}=0.211 \mathrm{x}+0.078$ \\
\cline { 2 - 3 } & $\mathrm{S}$ & $\mathrm{y}=0.317 \mathrm{x}+0.302$ \\
\cline { 2 - 3 } & $\mathrm{A}$ & $\mathrm{y}=0.418 \mathrm{x}+0.571$ \\
\hline \multirow{4}{*}{ B0-S0-E90 } & $\mathrm{W}$ & $\mathrm{Y}=0.7 \mathrm{x}+7.72$ \\
\cline { 2 - 3 } & $\mathrm{B}$ & $\mathrm{Y}=0.202 \mathrm{x}+0.436$ \\
\cline { 2 - 3 } & $\mathrm{S}$ & $\mathrm{Y}=0.321 \mathrm{x}+0.451$ \\
\cline { 2 - 3 } & $\mathrm{A}$ & $\mathrm{Y}=0.436 \mathrm{x}+0.571$ \\
\hline \multirow{5}{*}{ B0-S45-E0 } & $\mathrm{W}$ & $\mathrm{Y}=0.733 \mathrm{x}+10.759$ \\
\cline { 2 - 3 } & $\mathrm{B}$ & $\mathrm{Y}=0.207 \mathrm{x}+0.698$ \\
\cline { 2 - 3 } & $\mathrm{S}$ & $\mathrm{Y}=0.6854 \mathrm{x}+1.68$ \\
\cline { 2 - 3 } & $\mathrm{A}$ & $\mathrm{Y}=0.667 \mathrm{x}+1.821$ \\
\hline
\end{tabular}

Table 7. Discomfort of each work posture during the exposed time calculated by a regression equation[Ex: B0-S0-E45, B0-S0-E90, B0-S45-E0 / Unit: minute / Whole body(W), $\operatorname{Back}(\mathrm{B})$, Shoulder(S), Arm(A)]

\begin{tabular}{c|c|r|r|r|r}
\hline & $\begin{array}{r}\text { Time } \\
\text { (min.) }\end{array}$ & 1 & \multicolumn{1}{c|}{2} & \multicolumn{1}{c}{3} & 4 \\
\hline \multirow{4}{*}{ B0-S0-E45 } & $\mathrm{W}$ & 8.20 & 8.77 & 9.34 & 9.91 \\
\cline { 2 - 6 } & $\mathrm{B}$ & 0.29 & 0.50 & 0.71 & 1.14 \\
\cline { 2 - 6 } & $\mathrm{S}$ & 0.62 & 0.94 & 1.25 & 1.57 \\
\cline { 2 - 6 } & $\mathrm{A}$ & 0.99 & 1.41 & 1.83 & 2.24 \\
\hline & $\mathrm{W}$ & 8.42 & 9.12 & 9.82 & 10.52 \\
\cline { 2 - 6 } B0-S0-E90 & $\mathrm{B}$ & 0.64 & 0.84 & 1.04 & 1.24 \\
\cline { 2 - 6 } & $\mathrm{S}$ & 0.77 & 1.09 & 1.41 & 1.74 \\
\cline { 2 - 6 } & $\mathrm{A}$ & 1.36 & 1.80 & 2.24 & 2.67 \\
\hline & $\mathrm{W}$ & 11.49 & 12.22 & 12.96 & 13.69 \\
\cline { 2 - 6 } B0-S45-E0 & $\mathrm{B}$ & 0.91 & 1.11 & 1.32 & 1.53 \\
\cline { 2 - 6 } & $\mathrm{S}$ & 2.36 & 3.05 & 3.73 & 4.42 \\
\cline { 2 - 6 } & $\mathrm{A}$ & 2.51 & 3.18 & 3.84 & 4.51 \\
\hline
\end{tabular}

회귀식을 기초로 산출된 불편도 값들은 3.1.1절과 같이, 위험수준을 4 단계로 재분류하였다. 즉, 국소 신체 부위에 적 용되는 Borg's 10 points의 경우, 1수준은 0 0.7점 구간으 로, 2수준은 0.7 2.0점 구간으로, 3수준은 2.0 5.0점 구간 으로, 4수준은 5.0 10점 구간으로 구분하였다. 그리고 전체 신체 부위에 적용되는 Borg's RPE의 경우, 1수준은 1.0 
9.0점 구간으로, 2수준은 9.0 12점 구간으로, 3수준은 12 17점 구간으로, 4수준은 17 20점 구간으로 각각 나누었다.

위 결과들을 토대로 각각의 자세에서 4 단계 위험수준에 이르는 필요 노출시간을 정리하면 Table 8 과 같다. 자세에

Table 8. Each work posture's exposed time required for reaching risk levels in the fourth stage [Ex: B0-S0-E45, B0-S0-E90, B0-S45-E0 / Unit: minute / Whole body(W), Back(B), Shoulder(S), Arm(A)

\begin{tabular}{c|c|c|c|c|c}
\hline Posture & Part & Level 1 & Level 2 & Level 3 & Level 4 \\
\hline \multirow{5}{*}{ B0-S0-E45 } & $\mathrm{W}$ & $1 \sim 2$ & $3 \sim 7$ & $8 \sim 16$ & $17 \sim 21$ \\
\cline { 2 - 6 } & $\mathrm{B}$ & $1 \sim 2$ & $3 \sim 9$ & $10 \sim 23$ & $24 \sim 46$ \\
\cline { 2 - 6 } & $\mathrm{S}$ & 1 & $2 \sim 5$ & $6 \sim 14$ & 15 \\
\cline { 2 - 6 } & $\mathrm{A}$ & & $1 \sim 3$ & $4 \sim 10$ & $11 \sim 22$ \\
\hline & $\mathrm{W}$ & 1 & $2 \sim 6$ & $7 \sim 13$ & $14 \sim 17$ \\
\cline { 2 - 6 } & $\mathrm{B}$ & 1 & $2 \sim 7$ & $8 \sim 22$ & $23 \sim 47$ \\
\hline & $\mathrm{S}$ & & $1 \sim 4$ & $5 \sim 14$ & 15 \\
\cline { 2 - 6 } & $\mathrm{A}$ & & $1 \sim 2$ & $3 \sim 9$ & $10 \sim 20$ \\
\hline \multirow{5}{*}{ B0-S0-E45-E0 } & $\mathrm{W}$ & & 1 & $2 \sim 8$ & $9 \sim 12$ \\
\cline { 2 - 6 } & $\mathrm{B}$ & & $1 \sim 6$ & $7 \sim 20$ & $21 \sim 44$ \\
\cline { 2 - 6 } & $\mathrm{S}$ & & & $1 \sim 4$ & $5 \sim 11$ \\
\cline { 2 - 6 } & $\mathrm{A}$ & & & $1 \sim 4$ & $5 \sim 12$ \\
\hline
\end{tabular}

따라 신체 부위 별로 특정 불편도에 이르는 시간에 서로 차 이가 있으므로 가장 먼저 위험수준에 도달하는 부위 - 특정 자세에서 신체부담을 가장 빨리 느끼는 부위 - 를 선별하여 해당 자세의 노출시간에 따른 불편도로 최종 채택하였다.

각 자세 별로 노출시간에 따른 불편도 값을 기초로 위 험수준을 구분하여 정리하면 Figure 1 과 같고, Table 5 와 Figure 1을 종합하면 작업 자세 별 점수와 노출시간 별 점 수에 따른 두 가지의 체크리스트가 생성되며, 이 점수표를 정리하면 Figure 2와 같다. 첫 번째 경우는 작업 자세만 관 찰했을 때, Figure 2의 좌측 <자세 별 위험수준>에서 해당 작업 자세를 선택하여 위험수준을 판별하고, 두 번째 경우인 작업 자세와 작업시간(노출시간)을 동시에 관측을 하였다면 우측 <자세와 시간을 고려한 위험수준>에서 해당 작업 자세 와 작업시간(노출시간)을 함께 고려한 위험수준을 평가할 수 있도록 하였다.

즉, 작업 자세가 $\mathrm{B} 0-\mathrm{S} 0-\mathrm{E} 90$ 이고 10 분간 이 자세로 작 업을 하였다면, Figure 2에서 B0-SO-E90을 선택하고 다 음으로 노출시간 7 13분 사이의 조건을 추가로 선택하면 위험수준은 3수준에 해당되는데 이는 위험도를 'High(높음)' 으로 평가할 수 있다. B0-S120-E0 자세의 경우 고정된 자세로 1 분 이상 유지되는 경우 위험수준이 4 수준에 해당 되어 위험도가 "Very High(매우높음)"으로 평가됨으로 이 런 자세가 1 분 이상 유지되지 않도록 하여야 함을 보여준다.

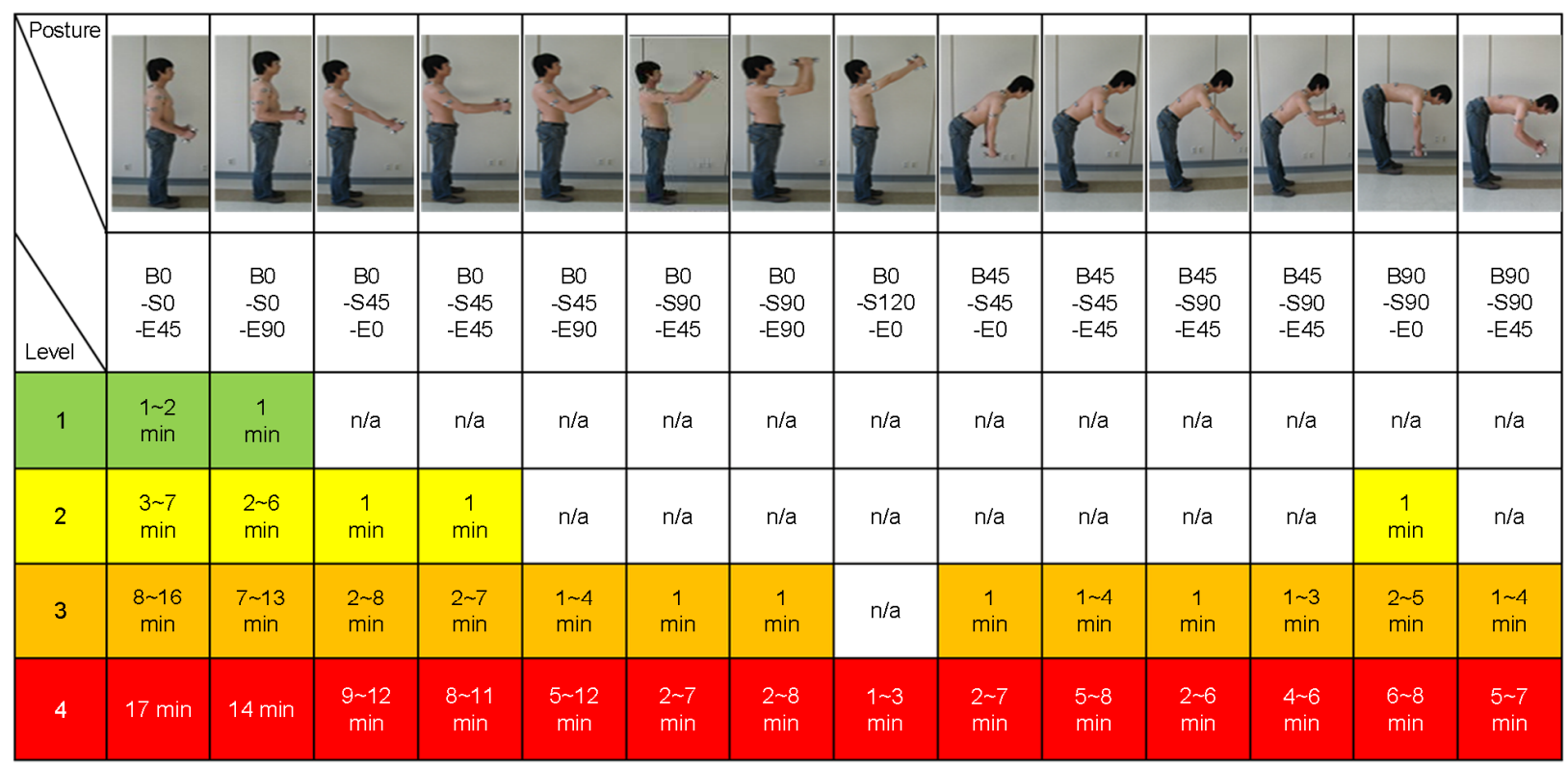

\begin{tabular}{|c|c|c|c|c|}
\hline Level & 1 & 2 & 3 & 4 \\
\hline Risk level & Medium & Little High & High & Very High \\
\hline
\end{tabular}

Figure 1. Risk levels considering postures and time 


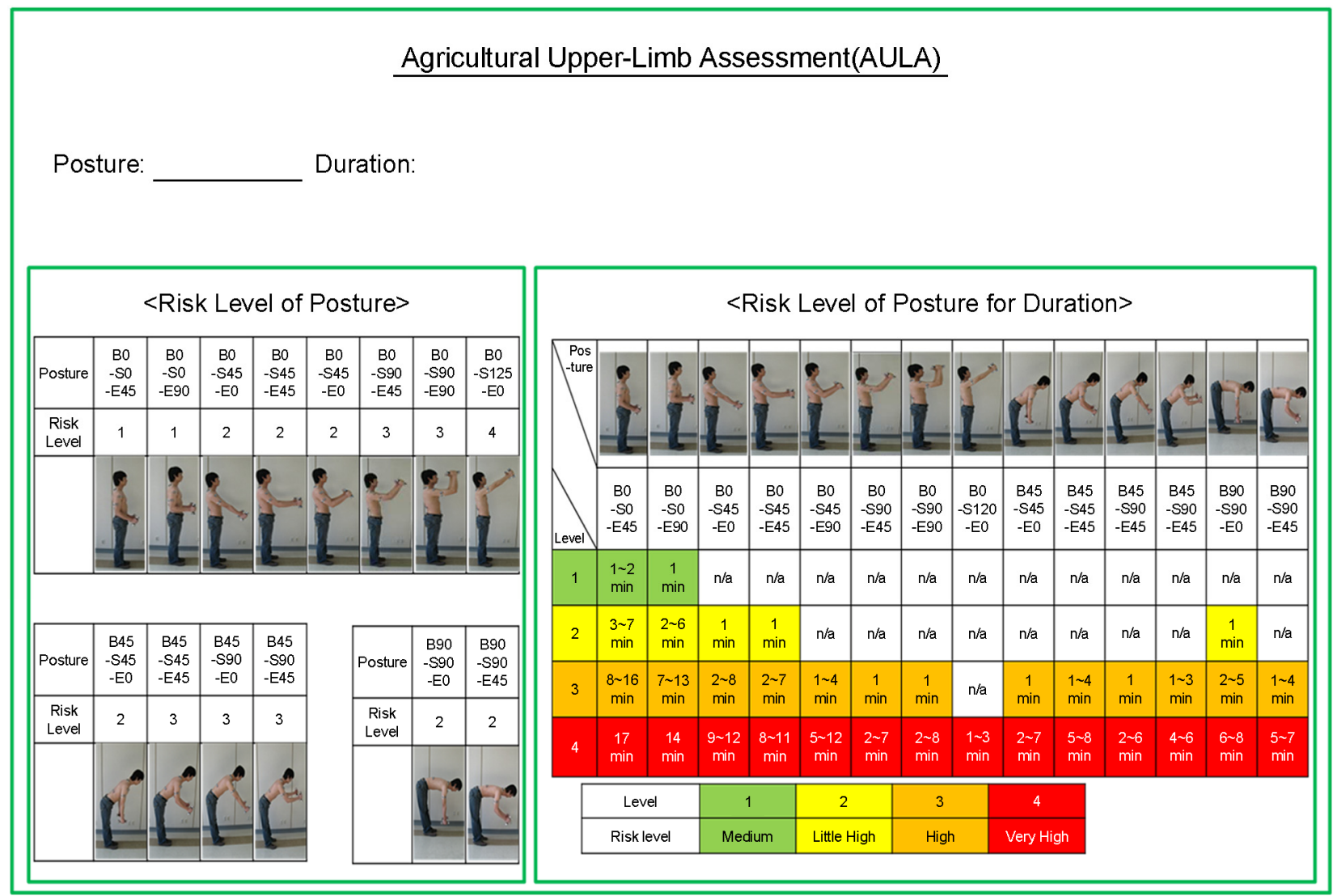

Figure 2. Risk level check list related to the upper limb posture in farm works

\subsection{Development of upper limb ergonomic assessment tool}

본 연구를 통해 개발된 상지 자세에 대한 인간공학적 평 가도구를 몇몇 작업자세의 상지 자세에 대해 평가하고, 기존 의 상지 평가가 가능한 체크리스트를 사용해 평가한 후 비 교 분석하였다(Table 9). Table 9의 사진과 같이 실제 농 작업에서 $\mathrm{B} 0-\mathrm{S} 0-\mathrm{E} 45$ 와 $\mathrm{B} 45-\mathrm{S} 90-\mathrm{E} 0$ 의 자세로 5분간 작업 자세를 비교 분석하였을 경우, $\mathrm{REBA}$ 의 경우 각 자세 에 따라 각각 1,4 점으로 평가되어 Action level이 1점으로 위험수준이 낮게 평가되고, 2점으로 위험수준이 보통으로 평가되어, 두 자세간에 평가의 차이가 발생하였다.

RULA의 경우 역시, 각 자세에서 score 2, 3점으로 평 가되어 action level이 1 과 2로 안전한 공정과 개선이 필요 한 것으로 평가되어, 두 자세간의 평가 차이가 발생하였다. OWAS 역시, REBA, RULA와 마찬가지로 각 자세의 score 가 1,2 점으로 다르게 평가되었지만, action level은 동일하 게 1 점으로 위험수준이 낮은 것으로 평가되어 두 자세의 차 이가 없는 것으로 나타났다.
반면, 본 연구에서 개발된 상지 자세 평가도구를 통해 각 자세를 평가한 결과 두 자세의 자세에 따른 점수는 1.25 점 과 2.50점으로 평가되었으며, action level 또한 각각 1 과 3으로 위험수준이 보통과 높음으로 나타나 B45-S90-E0 자세에서 높게 나타났다. 뿐만 아니라 시간에 따른 점수를 살펴보면, 각각 action level이 한 단계씩 상승하여 2 과 4 로 위험수준이 조금 높음과 매우 높음으로 나타났다.

Table 9. Comparison with the existing checklists

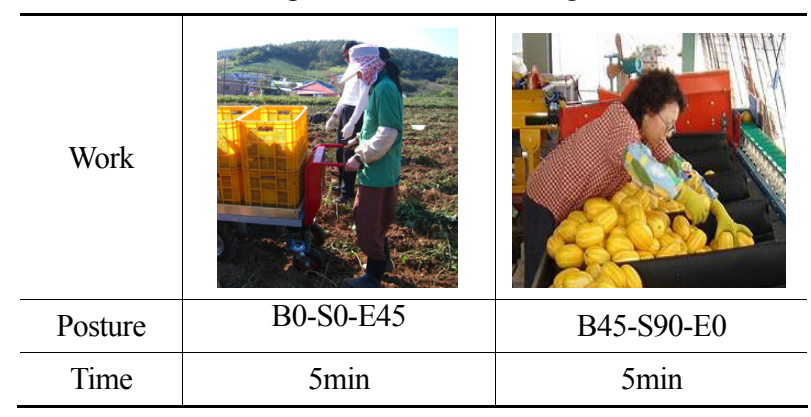


Table 9. Comparison with the existing checklists (Continued)

\begin{tabular}{|c|c|c|c|}
\hline \multicolumn{2}{|c|}{ REBA } & $\begin{array}{l}\text { REBA score: } 1 \\
\text { Action level: } 1 \\
\text { Risk level: low }\end{array}$ & $\begin{array}{c}\text { REBA score: } 4 \\
\text { Action level: } 2 \\
\text { Risk level: medium }\end{array}$ \\
\hline \multicolumn{2}{|c|}{ RULA } & $\begin{array}{c}\text { RULA score: } 2 \\
\text { Action level: } 1 \\
\text { Risk level: safety }\end{array}$ & $\begin{array}{c}\text { RULA score: } 3 \\
\text { Action level: } 2 \\
\text { Risk level: need } \\
\text { improvement }\end{array}$ \\
\hline \multicolumn{2}{|c|}{ OWAS } & $\begin{array}{l}\text { OWAS score: } 1 \\
\text { Action level: } 1 \\
\text { Risk level: low }\end{array}$ & $\begin{array}{l}\text { OWAS score: } 2 \\
\text { Action level: } 1 \\
\text { Risk level: low }\end{array}$ \\
\hline \multirow{2}{*}{$\begin{array}{l}\text { A } \\
\text { U } \\
\text { L } \\
\text { A }\end{array}$} & $\begin{array}{l}\text { Posture } \\
\text { score }\end{array}$ & $\begin{array}{l}\text { AULA score: } 1.25 \\
\text { Action level: } 1 \\
\text { Risk level: medium }\end{array}$ & $\begin{array}{c}\text { AULA score: } 2.50 \\
\text { Action level: } 3 \\
\text { Risk level: high }\end{array}$ \\
\hline & $\begin{array}{l}\text { Time } \\
\text { score }\end{array}$ & $\begin{array}{c}\text { Action level: } 2 \\
\text { Risk level: Little high }\end{array}$ & $\begin{array}{c}\text { Action level: } 4 \\
\text { Risk level: Very high }\end{array}$ \\
\hline
\end{tabular}

\section{Conclusion}

근골격계 위험요인을 평가하기 위한 평가도구들이 평가체 계를 범용으로 사용되며, 대부분 제조업체 근로자들을 대상 으로 개발되었기 때문에, 농작업 활동을 평가하기에 매우 제 한적이며 한계가 발생하였다. 따라서, 본 연구에서는 농작업 에 특성화된 상지 중심의 평가체계를 개발하고 적용하여, 농 작업 재해 중 농업인의 근골격계 증상 유병률과 신체발생 부 위에 대한 연구, 그리고 그에 대한 원인 등의 연구하고자 하였다.

본 연구의 3 단계 실험, 개발 그리고 적용을 통해 인간공 학적 상지 자세 평가도구를 완성하였다. 실험의 경우 선행연 구의 연구 방법과 동일한 방법이며, 평가도구 개발에 사용된 실험 결과 또한 선행연구의 결과를 사용하였다.

실험 결과 중 주관적 불편도를 살펴보면, 전신에 대한 불 편도는 어깨가 $90^{\circ}$ 이상일 때 주관적 불편도가 높게 나타났 다. 허리의 주관적 불편도는 허리 각도가 $45^{\circ}$ 일 때가 가장 높게 나타났으며, 어깨와 팔의 불편도는 어깨 각도가 커질수 록 불편도가 커지는 유사한 결과를 보였다. 심박수의 경우는 B0-S0-E90 자세에서 가장 작게 나타났으며, B0-S90$\mathrm{E} 45, \mathrm{~B} 0-\mathrm{S} 90-\mathrm{E} 90$ 등의 자세는 4점을 부여 받았는데, 이 는 주관적 불편도와 상당히 유사한 경향을 보이고 있다. 전 신과 허리, 어깨 그리고 팔에서 주관적 불편도가 높은 자세 들이 심박수 또한 높은 점수를 부여 받았으며, 주관적 불편 도가 낮은 자세들은 심박수 또한 낮은 점수를 부여 받았다.

위와 같이 실험 결과에 대해 점수를 분배하여 각 자세에 따른 점수를 정하였다. 자세 별 점수에 따라 위험수준을 1 (보통)에서 4 (매우 높음)로 구분하였고, 시간에 따른 위험수
준을 결정하기 위하여 3 분마다 측정된 주관적 불편도 결과 로 시간에 따른 불편도의 회귀식을 구하였다. 회귀식을 통해 시간 별 불편도를 추정하여 위험수준을 재분류 하였다. 이를 통해, 기존 평가도구들은 자세에 대한 평가만을 고려하였지 만, 본 연구의 평가도구들은 시간을 고려함으로 인해 보다 현실적인 평가가 가능하게 되었다.

개발된 상지 자세 인간공학적 평가도구를 실제 작업에 적 용하여 평가한 후, 기존 평가도구들의 결과와 비교, 분석하 였다. 비교, 분석에 사용된 자세는 본 연구의 실험 중 자세 별 점수가 2.50으로 위험수준이 높음에 해당하는 B45S90-E0의 자세와 자세 별 점수가 가장 낮은 1.25 로, 위험 수준이 보통에 해당하는 B0-S0-E45의 자세였다. OWAS 를 제외한 RULA와 REBA의 평가도구는 위험수준이 보통 인 자세와 위험수준이 높은 자세의 차이를 인지하여 본 연 구와 유사한 결과를 보였지만, 자세에 따른 평가 차이가 확 연하게 나타나지 않았다. 또한, 시간이 부여된다면, 아무리 위험수준이 낮아도 위험수준 정도에 상관없이 위험수준이 높아지는 결과를 보임에도 불구하고, REBA와 RULA는 시 간을 고려하지 못하는 것을 볼 수 있었다. RULA, REBA 그리고 OWAS의 평가도구는 자세에 따른 위험수준의 차이 가 확연하게 나타나지 않는 것은 기존 연구들의 한계점으로 인해 나타나는 결과로서, 점수의 체계를 신체 부위 별로 다 르게 하여 어느 특정 부위에 대해서만 편파판정을 하는 경 우가 발생하기 때문이다. REBA의 경우 윗팔과 몸통의 움직 임에 따라 1 4점으로 각도의 변화에 점수차이가 크게 나타 나며, RULA의 경우 목의 각도와 상박의 위치에 따른 점수 차이가 1 4점으로 크게 나타나기 때문에 초점에 맞춰진 자 세의 변화가 크지 않을 경우, 자세의 변화를 인식하는데 둔 감한 결과를 가져온다. 반면, 개발된 상지 자세 인간공학적 평가도구는 자세간의 차이를 분명하게 인식하였다. 본 연구 의 평가도구는 기존 평가도구와 같이 어느 특정 부위에 초점 을 맞춘 것이 아니라 각 부위에 따른 인체생리학적 결과를 균일하게 시간을 고려하여 시간이 지남에 따라 위험수준이 높아지는 결과를 통해 기존 평가도구들의 한계점을 극복할 수 있게 되었다.

다만, 본 연구에서 상지 자세를 선정하는데 있어 많은 제 약들로 인해 보다 다양한 자세를 고려하지 못하였으며, 연구 대상이 농작업 현실과 다른 젊은 대학생을 대상으로 구성되 어 있는 한계점을 가지고 있다. 하지만 평가도구의 타당성을 부여하기 위한 검증을 실시하여 현장에 적용한다면, 체계적 인 농업관련 작업에 대한 근골격계질환의 유발성에 대한 연 구를 발전시켜 다른 산업 분야에 비해 상대적으로 열악한 농작업 관련 근골격계질환을 예방하고 관리하는 수준을 향 상시킬 수 있을 것이다. 또한, 농작업 관리 실무자들이 농작 업의 위험성 평가 작업에 직접 참여하여 현장 실무 적용의 활성화를 기대할 수 있으며, 근골격계질환 위험요소를 가진 
농작업자들의 보다 객관적이고 효과적인 분석을 통해 근골 격계질환 유별율을 줄여 안전한 작업장으로의 개선효과를 기대할 수 있을 것으로 보인다.

\section{Acknowledgements}

This work was supported by Joint Research work of Agricultural Science and Technology Development of Rural Development Administration(RDA)(PJ0064222010, 2010).

\section{References}

Carpenter, J. E., Blasier R. B. and Pellizzon G. G., The effects of muscle fatigue on shoulder joint position sense, American Journal of Sports Medicine, 26, 262-265, 1988.

Chaffin, D. B., Andersson, G. B. J. and Martin, B. J., Occupational Biomechanics, 3rd ed., John Wiley \& Sons, Inc., New York, 1999.

Hyun, S. D. and Kim J. Y., The effect of high heel on back muscle fatigue, Journal of the Ergonomic Society of Korea, 16(3), 37-48, 1997.

Keyserling, W. M., Brouwer, M. and Silverstein, B. A., A checklist for evaluating ergonomic risk factors resulting from awkward postures of the legs, trunk and neck, International Journal of Industrial Ergonomics, 9, 283-301, 1992.

Kong, Y. K., Han, J. G. and Kim, D. M., Development of an Ergonomic checklist for the investigation of work related lower limb disorders in farming-ALLA: Agricultural Lower-Limb Assessment, Journal of the Ergonomic Society of Korea, 29(6), 1-9, 2010.

Kong, Y. K., Lee, S. J., Lee, K. S. and Seo, M. T., The effects of coordinated upper-limb postures of back, shoulder, and elbow angles on the subjective discomfort rating, heart rate, and muscle activities, Journal of the Ergonomics Society of Korea, (submitted), 2011.

KOSHA Code H-30-2003, Korea Occupational safety \& Health Agency, 2003.

KOSHA Code H-31-2003, Korea Occupational safety \& Health Agency, 2003.

Minning, S., Eliot, C., Uhi, T. and Malone, T., EMG analysis of shoulder muscle fatigue during resisted isometric shoulder elevation, Journal of Electromyography and Kinesiology, 17, 153-159, 2007.

Punnett, L., Ergonomic stressors and upper extremity disorders in vehicle manufacturing: cross sectional exposure-response trends, Occupation and Environmental Medicine, 55, 414-420, 1998.

Öberg, T., Sandsjö, L. and Kadefors, R., EMG mean power frequency in non-fatigued trapezius muscle, European Journal of Applied Physiology, 61, 362-369, 1990.

Tomas, E., Hanse, J. and Kadefors, R., Musculoskeletal symptoms due to technical preconditions in long cycle time work in an automobile assembly plant: a study of prevalence and relation to psychosocial factors and physical exposure, Applied Ergonomics, 30, 443-453, 1999.

\section{Author listings}

\section{Yong-Ku Kong: ykong@skku.edu}

Highest degree: $\mathrm{PhD}$, Department of industrial and Manufacturing Engineering, Pennsylvania State University

Position title: Professor, Department of Industrial Engineering Sungkyunkwan University

Areas of interest: Physical Ergonomics, WMSDs, Finger/Hand Modeling

Soo-Jin Lee: sjlee@hanyang.ac.kr

Highest degree: $\mathrm{PhD}$, College of Medicine, The Catholic University of Korea

Position title: Professor, Department of Occupational and Environmental Medicine, College of Medicine Hanyang University

Areas of interest: Occupational and Environmental Medicine,

Occupational disease

Kyung-Suk Lee: leeks81@korea.kr

Highest degree: $\mathrm{PhD}$, Department of Clothing and textiles, Seoul National University

Position title: Senior Researcher, Department of Agricultural Engineering RDA

Areas of interest: Occupational safety and health, Management system

Jun-Goo Han: babby2002@skku.edu

Highest degree: MS, Department of Industrial Engineering Sungkyunkwan University

Position title: Researcher, Department of Industrial Engineering Sungkyunkwan University

Areas of interest: Physical Ergonomics, WMSDs

Dae-Min Kim: kimdaemin@skku.edu

Highest degree: MS, Department of Industrial Engineering Sungkyunkwan University

Position title: $\mathrm{PhD}$. Candidate, Department of Industrial Engineering Sungkyunkwan University

Areas of interest: Physical Ergonomics, WMSDs, Finger/Hand Modeling

Date Received : 2011-06-23

Date Revised :2011-07-26

Date Accepted : 2011-07-26 